\title{
An interdisciplinary approach to the study of physiological problems of students in the context of digitalization
}

\author{
Elena Matsyuk* \\ Don State Technical University, 344002, Rostov-on-Don, Russia
}

\begin{abstract}
The relevance of the research is due to the lack of theoretical understanding of the learning process transformation of elementary school children with writing and reading disorders (dysgraphia and dyslexia) in the context of the digitalization of the education system. The article provides an extended analysis of data on the potential impact of the intensification of the introduction of digital technologies on the communicative development of students aged 8-10 years. The prevalence of dysgraphia and dyslexia among elementary school children in various countries of the world was looked upon. The scientific novelty of the article lies in the systematization of the research results of domestic and foreign authors studying the issues of understanding the structure, prevention, and overcoming of dysgraphia and dyslexia from the point of view of a targeted complex interdisciplinary approach, including neurological, neuropsychological aspects and basic speech therapy methods of speech therapy for diagnostics and correction of writing and reading disorders in conditions of digitalization of education.

The study of the vectors of modern approaches to the neuropsychological classification of writing and reading disorders leads to the conclusion that the use of a targeted integrated interdisciplinary approach in the context of digitalization of education allows us to consider all the criteria that are significant for drawing up effective correctional programs for overcoming dysgraphia and dyslexia. These are such criteria as age and psychological characteristics of the personality of students aged 8-10 years, the peculiarities of self-determination, and the value system of schoolchildren of the "digital" generation, communicative, cognitive, neuropsychic characteristics of students with dysgraphia and dyslexia.
\end{abstract}

\section{Introduction}

Digitalization, which inevitably follows informatization and computerization, has influenced all spheres of human life in the 21 st century. The continuous transformation of information into digital form has served to update and generate new ways of communication, working conditions, and social life of a modern person, and digital devices have become an integral part of his identity. At the same time, the main audience of users of digital technologies today is made up of people born in the 90 s of the XX century and later, whom the Canadian scientist

${ }^{*}$ Corresponding author: elenamacjuk@yandex.ru 
Don Tapscott proposed to call "Net Generation" [1]. Communication and activities of the younger generation are mediated by gadgets, which are new "cultural and historical tools" in the light of L.S. Vygotsky and certainly influenced the personal self-determination of modern children [2]. Special attention of the state and society today is focused on the digitalization of education as a repository of the cultural code and a link between the past, present, and future in the context of the weakening of the role of traditions in modern society. The digital transformation that the educational environment has undergone still requires scientific understanding, research is being carried out actively studying various aspects of this phenomenon. Emphasizing the importance of using digital technologies in the educational process at the present stage and the need to improve the corresponding competencies among schoolchildren [3,4], various authors consider new challenges facing the education system [5] and the ability to respond to them [6]. There is a lack of readiness of teachers to introduce digital technologies in schools [7], as well as the presence of factors constraining the development of digital technologies in education, such as the need for investment and a shortage of specialists [8]. The content of new concepts is revealed: "digital literacy" [9], "digital school" [10]. In 2019, a group of Russian scientists conducted a comprehensive analysis of the approaches and standards of digital education, considering modern platforms, models, and technologies [11]. The digitalization of public life in Russia has become one of the priority national projects and by the decree of the President of the Russian Federation of 2017, the strategy for the development of the information society in the Russian Federation for 2017-2030 was determined. Earlier, in 2016, the most important project in the field of education "Modern digital educational environment of the Russian Federation" was approved and in the same year the implementation of the sectoral program "Russian electronic school" was started.

However, the real challenge for the education system in Russia, like most developed countries, was the emergency transition to online learning due to the global world crisis associated with the COVID-19 pandemic. Such "shock" digitalization, according to researchers, not only served to intensify the introduction of digital technologies in education and made it possible to assess the effectiveness of the transformations that have occurred, but also turned out to be "the most effective tool for preserving both the stability of the education system and cultural continuity at the civilizational level in a crisis" [12]. At the same time, several negative factors emerged. The authors of studies carried out over the past year and aimed at analyzing the impressions of direct participants in the educational process from the forced intensive interaction with digital education emphasize that by providing access to a single space of educational resources and stimulating the personal development of students, digital technologies, used so intensively, caused students "Difficulties in self-organization and motivation in the process of online learning", as well as "lack of socialization and an overabundance of virtual communication, which was confirmed by $70.2 \%$ of respondents" [13]. According to one of the polls, $62.7 \%$ of parents of students, $40.4 \%$ of students, and $35.5 \%$ of teachers were skeptical about online learning and would not like to continue their studies or work in this format [12].

However, the most vulnerable category, in our opinion, turned out to be primary school students, children of 8-10 years old, living the process of forming the prerequisites for an individual to reach a new level of mastering social reality. An important indicator of the adaptive equipment of personality for this category of children is communication, which is emphasized in the works of domestic researchers (Petrovskaya L.A., Leontyev A.A., Shapovalova M.P., Lemyaskina N.Ya.), who note the relationship of communicative development with the formation of the motive of success and the formation of the value component of communication, the development of the regulatory function of behavior during primary school age. According to other researchers [14,15], there is insufficient data on the features of the normative and deviating speech ontogenesis of modern children. The younger 
generation today is actively using a new type of communication, which has become an integral part of the life of society. This is display communication, containing elements of both oral and written speech, and is a sign system that expands the possibilities of communication, but at the same time reduces traditional types of communication. Modern children begin mastering this type of communication much earlier than mastering reading, writing, and sometimes oral speech. Modern didactics need to develop new principles, methods, techniques of digital teaching, and upbringing.

Since the basic trend of the modern education system is its humanization, and the economic development of a country with a democratic system of government sees society as interacting microsociums, where the ability of people to independently determine their position in society is equality, models of joint learning have appeared in the world education system for children with normotypical development and with disabilities. Possible barriers to school and social adaptation for younger students in the general educational environment are formed due to the cognitive and communicative characteristics of their development. The most common causes of school problems are disorders of verbal - speech or writing - speech activity, caused by the most complex polymodal cerebral organization of the processes of writing and reading.

\section{Results}

After the detailed studying of the problem of teaching the category of primary school children with speech disorders, G.V. Chirkina, as part of the work on the Federal State Educational Standard (FSES), back in 2012, proposed introducing the definition of "special educational needs" (SEN) of a child with a particular speech disorder, as a new parameter "affecting the variability of learning and choice of the standard option" [14, p. 156]. G. V. Chirkina pointed to the variety of consequences caused by speech disorders and negatively affecting the social adaptation of the student, emphasizing that "a significant part of speech disorders leads to specific learning difficulties since chronic writing failure (and often in combination with reading difficulties - dyslexia) forms persistent negative reaction to learning at school" [14, p.161].

The issues of diagnosing school failure, disorders of mastering the processes of reading and writing (dyslexia and dysgraphia) in children with speech disorders at different times were studied by prominent Russian scientists and practitioners in the field of speech therapy, psychology, neuropsychology: G.A. Kashe, N.A. Nikashina, L.N. Efimenkova, R. I. Lalaeva, O. E. Gribova, A. N. Kornev, T. V. Akhutina, I. N. Sadovnikova, T. A. Fotekova and others.

The data of the Russian sociological survey on the problems of writing and reading disorders in children, conducted in 2019 by a group of researchers among the population of Russia and the professional audience, demonstrated a low awareness of the Russian society in matters of dysgraphia and dyslexia. Only $17 \%$ of the population are aware of these concepts, $83 \%$ do not know about them. Among pedagogical professionals, teachers consider themselves the least prepared to help children with dysgraphia and dyslexia ( $43 \%$ of the respondents do not have the opportunity to help children with such disorders of school skills) [15].

A study by the Ministry of Health of Russia states the presence of dysgraphia and dyslexia in most students with manifestations of school maladjustment, which, according to neurologists and pediatricians, occurs in $31.6 \%$ of Russian schoolchildren and arises from the immaturity of certain higher mental functions, designated as minimal cerebral dysfunction (MMD). Within the MMD group, children with attention deficit hyperactivity disorder (ADHD) are distinguished. Those suffering from a concentration defect, impulsive behavior, problems in relationships with others, schoolchildren with ADHD in $66 \%$ 
foundwriting and reading disorders. [16]. Correction of the disorder of school skills in schoolchildren with MMD and ADHD, according to neurologists and neuro pediatricians, requires complex medical, psychological, and pedagogical influences. These data correlate with the results of studies by foreign authors R. I. Nicolson and A. J. Fawcett, who asserts that in groups of students suffering from attention deficit and developmental coordination disorder, the prevalence of developmental dyslexia may increase to 10 percent or more [17].

Other foreign researchers, in particular Luz Rello, characterize dysgraphia and dyslexia as a neurological inability of children to learn, expressed in the difficulties of accurate word recognition and poor spelling of new words or words that are complex in terms of soundsyllabic composition, as well as phonetically and spelling similarities [18]. The prevalence of dysgraphia and dyslexia, according to Luz Rello, among the US population varies from 10 to $17.5 \%$, in the Hispanic population - from 7.5 to $11 \%$, [18] In English-speaking countries, dyslexia occurs in the population in 10-15\% [19]. A nationwide Polish study on the diagnosis of dyslexia and dysgraphia in schoolchildren showed that $13.1 \%$ of children suffer from this disorder [20].

The modern view of domestic researchers on the structure of the processes of reading, writing, as well as the violation of the formation of these skills, is based on the neuropsychological approach and the fundamental works of A.R. Luria, E.G. Simernitskaya, A.V. Semenovich, and other domestic neuropsychologists. Thus, T.V. Akhutina, pointing out the methodological accuracy of the systemic and dynamic approach to the study of the higher mental functions of A.R. Luria emphasizes its relevance at a new level of knowledge. Considering the functional composition of writing and its dynamic structure in the paradigm of the theory of 3 brain blocks A.R. Luria, T.V. Akhutina analyzes the difficulties of writing and reading from the point of view of the operational component of the brain blocks: maintaining the active tone of the cortex during writing (1st brain block); the processing of auditory-speech, kinesthetic, visual or visual-spatial information (2nd brain block); serial organization, as well as programming and control of voluntary actions (3rd brain block) [21].

In Russian literature, the main attention in describing dysgraphia and dyslexia is paid to its type, which is associated with specific errors due to violations of language analysis and synthesis: the student, perceiving the whole word as a whole and relying on its semantic side, ignores the phonetic composition of the word or cannot compose a word of an individual letters (sounds).From the point of view of the neuropsychological approach, this form of dysgraphia is based on the insufficient development of the processes of processing auditoryspeech information, namely, phonemic analysis. Foreign authors also call "phonological dyslexia/dysgraphia" the most common disorder. Anne O'Hare emphasizes that children with poor phonological awareness have problems with acquiring the skills of combining speech sounds with rhyme and alliteration and recognizing syllables, which, according to the researcher, is accompanied by a short-term verbal memory deficit [19]. These errors are often combined with the difficulties of kinesthetic analysis, i.e., speech and motor disorders. According to Klim-Klimaszewska A., Nazaruk S., some schoolchildren experience serious difficulties in mastering the skills of continuous writing and spelling. [20] Anne O'Hare describes cases of dyspraxic dysgraphia, which is expressed as "uncertainty about the movement required to form letters, words, and spacing" [19, p.341].

Immaturity of visual function and difficulties in processing visual-spatial information, visual instability of perception in children with dysgraphia and dyslexia are also noted in the works of Anne O'Hare. According to her, children report that "small letters seemed to move, change places, and merge" [19, p. 343].

Difficulties in writing due to the weakness of the programming and control functions are rarely described, but in the practice of speech therapy, they are often encountered. Perhaps 
teachers attribute these cases to the group of dysorphographs - errors of noncompliance with spelling rules. Pupils experiencing such difficulties make mistakes associated with difficulties in switching, especially when fatigued: there is a repetition of the type of task, stuck on the elements of letters, syllables, words, i.e. systemic and elementary perseverations, which, according to neuropsychologists, indicate the lack of formation of the operations of the entire III block of the brain - both programming and control, and the serial organization of movements.

R. I. Nicolson and A. J. Fawcett describes this phenomenon in terms of the automation deficit hypothesis. In their opinion, children with dyslexia and dysgraphia experience difficulties in practicing skills in a variety of areas (motor, cognitive) despite long-term practice under constant conditions [20].All listed operational disorders of the brain blocks, leading to functional disorders of reading and writing, can be combined, causing severe mixed forms of dysgraphia and dyslexia.

Due to the variety of factors that cause writing and reading disorders, this problem is being studied in an interdisciplinary aspect. This research is being conducted by psychologists, educators, physicians, primarily neurologists, and psychiatrists. They pay special attention to the constant stressful situation of teaching children with dysgraphia and dyslexia due to systematic failures in school, causing the consolidation of such traits as selfdoubt, anxiety, and low self-esteem [16]. These data correlate with the results of our study to identify the characteristics of self-acceptance by younger schoolchildren with dysgraphia and dyslexia. Diagnostics of the unconscious emotional components of the personality through the projective technique "Self-portrait" revealed in children with writing and reading disorders the presence of moderately expressed fears in $66 \%$ of cases, low self-esteem in $49 \%$, moderately expressed aggression in $45 \%$, and moderately expressed dependence in $77 \%$ in comparison with their peers who have no problems in the formation of school skills [22].

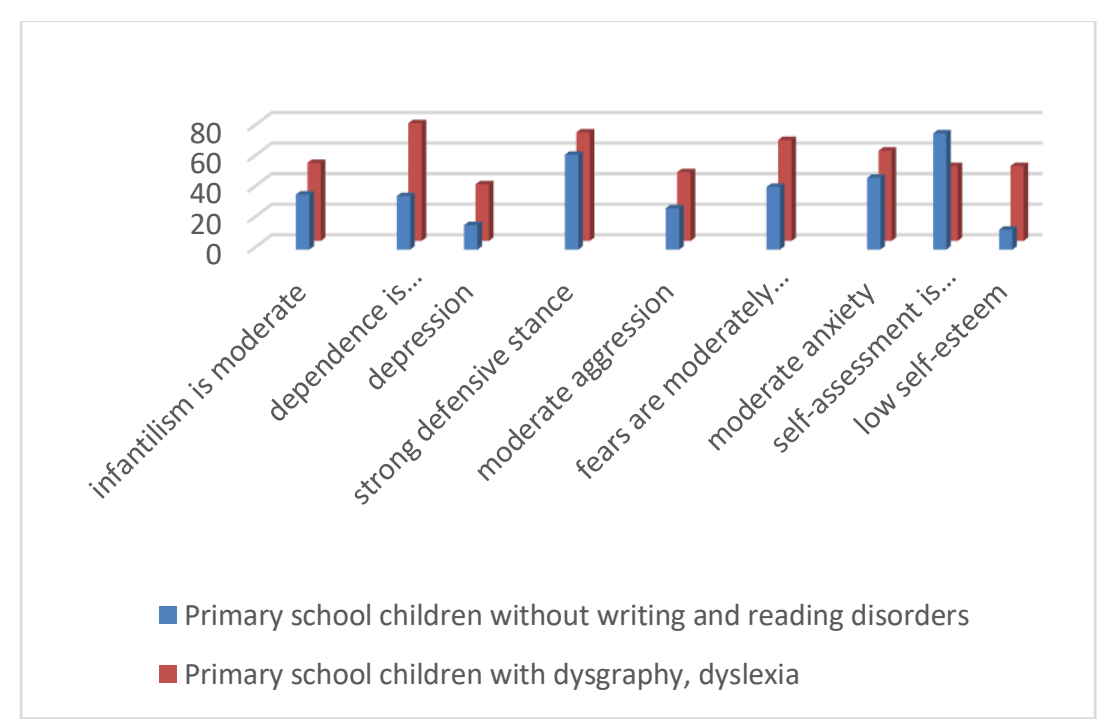

Fig. 1. Comporative analyses of project method of Self-portraite done by primary school children with dysgraphy, dyslexia and school children without writing and reading disorders

\section{Discussion}


The data presented by speech therapists at the Center for Speech Pathology and Neurorehabilitation O. I. Dolgova, and co-authors indicate that $80 \%$ of schoolchildren with dysgraphia and dyslexia entering the neurorehabilitation course have a low level of formation of motivational attitudes towards learning activities. Speech therapists of The Center for Speech Pathology and Neurorehabilitation argue that the ultimate goal of helping schoolchildren with dysgraphia and dyslexia is not academic success, but a persistent positive motivation for the educational activities of this category of children, achieved through the use of a targeted integrated interdisciplinary approach [23].

This approach is also practiced in Dutch speech and hearing centers when the diagnosis of the adaptability of children with a language disorder or suspicion of it consists not only of assessing speech and language skills but also cognition, behavior, hearing (and other physical aspects), as well as family characteristics. This examination involves a speech therapist, developmental psychologist, and audiologist [24]. Anne O'Hare believes that in order to identify the predisposing factor for dyslexia, it is necessary to have a consultation with a pediatrician who is able to offer an adequate intervention strategy from a variety of existing theories [19].

Russian neurologists and pediatricians concluding that helping children with disorders of school skills should be timely and comprehensive. Such assistance should combine the methods of medical and psychological, medical, and pedagogical, social and speech therapy intervention. They emphasize the role of family participation, the coordination of the efforts of parents with the actions of specialists. Early detection and intervention of cognitive, emotional, and behavioral disorders in children with dysgraphia and dyslexia has major importance, as well as preparation of an individual plan of complex measures for each child [16].

Russian neuropsychologists note two points of equal importance in forming an effective program for the intervention of dysgraphia and dyslexia. Firstly, the identification of the psychological structure of the syndrome of deviation of higher mental functions plays a major role in the process, as well as the determination of the primary defect, its systemic consequences, and compensatory rearrangements. Secondly, intervention of writing difficulties should include work not only on writing but on the entire syndrome of deviation in the development of higher mental functions, considering the weak link and relying on intact links.

\section{Conclusion}

Summing up the results of the extended analysis of the problem of writing and reading disorders in primary schoolchildren in the context of digitalization of education, it is necessary to note the following aspects of organizing effective prevention and intervention of dysgraphia and dyslexia at an early stage of education:

1. Digital technologies in education contribute to providing access to a single space of educational resources and stimulate the personal development of children. However, with the intensive use of digital technologies, as in the period of forced widespread distance learning in connection with the COVID-19 pandemic, they have a negative impact on children. It causes an overabundance of virtual communication and an acute lack of socialization. Particular difficulties in self-organization and motivation for learning activity in such conditions are experienced by schoolchildren with communication disorders, in particular, younger schoolchildren with impaired verbal and written speech activity. Though, the planning of effective educational programs today will be advisable considering the cognitive and communicative characteristics of modern children of the "digital" generation and the inclusion of network forms of communication and display communication in the learning process. 
2. Writing and reading disorders are multifactorial disorders that affect not only the cognitive development of the child, but also the emotional, behavioral sphere of the developing personality. They also have a biomedical basis. Because of that, an adequate approach to the study of dysgraphia, dyslexia, and the search for ways to correct the disorder is a purposeful comprehensive interdisciplinary approach that combines research and methodological recommendations of primary school teachers and speech therapists, neurologists and pediatricians, neuropsychologists, and support specialists (tutors, social workers). Of great importance are the involvement of the family in the system of helping the child and the awareness of relatives about the essence of dysgraphia and dyslexia, a consistent and complex system for overcoming these disorders. Every schoolchild with reading and writing disorders needs an individual intervention program.

3. Intervention program with children who have difficulties in writing and reading is effective if it considers the entire complex of symptoms, of which this or that dysgraphia is a part. It is advisable to build a correctional individual program in speech therapy practice, identifying the primary dysfunction, considering the intact links of and relying on a professionally made neuropsychological examination of the child. Such consideration is possible if the speech therapist has a professionally made neuropsychological conclusion.

4. Achieving the effectiveness of programs to overcome dysgraphia and dyslexia cannot be limited to the indicators of the child's academic success. The ultimate goal is to form a schoolchild's persistent interest and motivation for learning activities. This task is solved by a comprehensively organized assistance program based, among other things, on the knowledge of the psychological characteristics of children of primary school age who have writing and reading disorders.

\section{References}

1. D. Tapscott, Grown Up Digital: How the Net Generation is Changing Your World (McGraw Hill Education, New York, 2008)

2. O.N. Tomyuk, M.A. D'yachkova, N.B. Kirillova, A.Yu. Dudchik, Prospects for Science and Education 6(42), 422-434 (2019). doi: 10.32744/pse.2019.6.35

3. A.O. Hansen, Technology and Society 10(3), 207-218 (2017)

4. L. Ilomäki, M. Lakkala, Research and Practice in Technology Enhanced Learning 13, 25 (2018). DOI: 10.1186/s41039-018-0094-8

5. E.Conte, A.C. Habowski, M.B. Rios, Revista Ibero-Americana de Estudosem Educacao 14(1), 31-45 (2019). doi: 10.21723/riaee.v14i1.11110

6. V.N. Goncharov, Philosophical Education 1, 135-139 (2018)

7. R.R. Chiossi, C.S. Costa, Texto Livre: Linguagem e Tecnologia 11(2), 160-176 (2018). doi: 10.17851/1983-3652.11.2.160-176

8. A.P. Lunev, A.V. Koksharov, Big Data and digital technologies in education: advantages and problems of implementation (In: Okladnikova, S. V. (ed.) Current issues of using technologies of data analysis and artificial intelligence, pp. 82-86. Individual entrepreneur Sorokin Roman Vasilievich, Astrakhan, 2018)

9. A. List, Computers \& Education 138, 146-158 (2019). doi: 10.1016/j.compedu.2019.03.009

10 N.I. Anurova, Digital technologies in education(In: Ershova, R. V. (ed.) Digital society as a cultural and historical context of human development, pp. 29-32. State educational institution of higher education of the Moscow region "State Social and Humanitarian University", Kolomna, 2018) 
11. Yu.D. Romanova, A.A. Nedelkin, V.G. Gerasimova, L.P.Dyakonova, N.A. Zhenova, P.E. Koval, I.G. Lesnichaya, T.Sh. Shikhnabieva, S.S. Khachaturova, P.A. Muzychkin, Plekhanovsky Scientific Bulletin 1, 104-121 (2019)

12. V.L. Nazarov, D.V. Zherdev, N.V. Averbuh, The Education and Science Journal 23(1), 156-201 (2021). doi: 10.17853/1994-5639-2021-1-156-201

13. S.R. Usmanov, World of Science, Culture, Education 1(62), 160-161 (2017).

14. G.V. Chirkina, Uchyonyezapiski 2, 155-166 (2012)

15. O.A. Velichenkova, T.V. Ahutina, M.N. Ruseckaya, Z.V. Gusarova, Special education 3, 36-49 (2019). doi: 10.26170/sp19-03-03

16. N.N. Zavadenko, Pediatrician practice 3, 60-70 (2016)

17. R.I. Nicolson, A.J. Fawcett, Cortex 47 (1), 117-127 (2011). doi: 10.1016/j.cortex.2009.08.016

18. L. Rello, Procedia Computer Science 27, 74-83 (2014). doi: 10.1016/j.procs.2014.02.010

19. A. O’Hare, Occasional Review 20 (7), 338-343 (2010). doi: 10.1016/j.paed.2010.04.004 2.

20. A. Klim-Klimaszewska, S. Nazaruk, Early assessment of the risk of dyslexia and dysgraphia among children aged 5-6 in the aspect of educational and therapeutic work of kindergartens, In: Society. Integration. Education: Proceedings of the International Scientific Conference 2, 558-573 (2018)

21. T.V. Ahutina, Writing disorders: diagnosis and intervention. Topical issues of speech therapy practice, In: Central mechanisms of speech: Methodological materials of the scientific and practical conference dedicated to the 100th anniversary of Professor N.N. Traugott (pp. 225-246). Aktsioneri K, St. Petersburg, (2004)

22. E. Matsyuk, M. Yelagina, Features of self-attitude in primary school children with dysgraphia and dyslexia in the conditions of digitalization of education, In: Innovative Technologies in Science and Education (ITSE-2020), E3S Web Conf. EDP Sciences, Les Ulis 210, 18061 (2020). doi: 10.1051/e3sconf/202021018061

23. O. I. Dolgova, E.V. Ziborova, S. I. Petrichenko, Methods for the formation of persistent motivation in group lessons in the system of complex neurorehabilitation in children with various forms of dysgraphia, dyslexia as part of an intensive course (In: Velichenkova, O. A., Lagutina, A. V. (eds.) Reading in the digital age (pp. 103-107). Moscow, 2018)

24. K. Wiefferink, Van Beugen C., Wegener Sleeswijk B., E. Gerrits, International Journal of Language and Communication disorders 55(4), 573-582 (2020) 